\title{
Functional Morphology of the Sonic Apparatus in the Fawn Cusk-eel Lepophidium profundorum (Gill, 1863)
}

\author{
Michael L. Fine, ${ }^{1 *}$ Hsung Lin, ${ }^{1}$ Brian B. Nguyen, ${ }^{1}$ Rodney A. Rountree, ${ }^{2}$ \\ Timothy M. Cameron, ${ }^{3}$ and Eric Parmentier ${ }^{4}$
}

${ }^{1}$ Department of Biology, Virginia Commonwealth University, Richmond, Virginia 23284-2012
${ }^{2}$ Marine Ecology and Technology Applications, 23 Joshua Lane, Waquoit, Massachusetts 02536
${ }^{3}$ Department of Mechanical Engineering, Kettering University, Flint, Michigan 48504
${ }^{4}$ Laboratoire de Morphologie Fonctionelle et Evolutive, Université de Liège, B-4000 Liège, Belgium

ABSTRACT Recent reports of high frequency sound production by cusk-eels cannot be explained adequately by known mechanisms, i.e., a forced response driven by fast sonic muscles on the swimbladder. Time to complete a contraction-relaxation cycle places a ceiling on frequency and is unlikely to explain sounds with dominant frequencies above $1 \mathrm{kHz}$. We investigated sonic morphology in the fawn cusk-eel Lepophidium profundorum to determine morphology potentially associated with high frequency sound production and quantified development and sexual dimorphism of sonic structures. Unlike other sonic systems in fishes in which muscle relaxation is caused by internal pressure or swimbladder elasticity, this system utilizes antagonistic pairs of muscles: ventral and intermediate muscles pull the winglike process and swimbladder forward and pivot the neural arch (neural rocker) above the first vertebra backward. This action stretches a fenestra in the swimbladder wall and imparts strain energy to epineural ribs, tendons and ligaments connected to the anterior swimbladder. Relatively short antagonistic dorsal and dorsomedial muscles pull on the neural rocker, releasing strain energy, and use a lever advantage to restore the winglike process and swimbladder to their resting position. Sonic components grow isometrically and are typically larger in males although the tiny intermediate muscles are larger in females. Although external morphology is relatively conservative in ophidiids, sonic morphology is extremely variable within the family. J. Morphol. 000:000-000, 2007. (c) 2007 Wiley-Liss, Inc.

KEY WORDS: sonic muscle; Ophidiiformes; swimbladder; sound production; antagonistic muscles; acoustic communication; pivot joint

The frequency spectrum of fish sounds produced by swimbladder vibration is determined as a forced response to sonic muscle contraction and swimbladder properties (Sprague, 2000; Fine et al., 2001, 2004). The requirement for sonic muscles to drive each sound cycle has selected for extreme speed (Fine et al., 2001), and fish sonic swimbladder muscles are considered the fastest muscles in vertebrates (Tavolga, 1964; Rome and Linstedt, 1998; Ladich and Fine, 2006). In fishes that make long duration tonal sounds (e.g., toadfish, midship- man, mormyrids, gurnards and searobins), the muscle contraction rate sets the fundamental frequency (Skoglund, 1961; Crawford and Huang, 1999; Bass and McKibben, 2003; Amorim and Hawkins, 2005); i.e., simultaneous contraction of paired sonic muscles at $200 \mathrm{~Hz}$ will drive a harmonic sound with a fundamental frequency of 200 $\mathrm{Hz}$. The northern searobin alternates muscle contraction so that the fundamental frequency is double the rate of individual contraction (Bass and Baker, 1991; Connaughton, 2004). More commonly, fish sounds are produced as a series of short-duration wide-band pulses (Winn, 1964). In weakfish (family Sciaenidae), each sound pulse is driven by a single muscle twitch, and the dominant frequency appears to be determined by timing characteristics of the sonic muscle twitch rather than bladder resonance (Connaughton et al., 2002) suggesting a similar mechanism to multicontraction tonal sounds. Rather than waiting for the contraction of a muscle antagonist, muscle relaxation and hence the relaxation component of a twitch sound (Fine et al., 2001) is caused by bladder elasticity or pressure built up in the bladder by contraction of sonic muscles. Dispensing with antagonist contraction removes the inertia that is otherwise involved in a change of muscle direction necessary to complete a sound cycle. Therefore, the timing of the muscle contraction-relaxation cycle typically places a ceiling on the maximum fundamental in longer-duration tonal sounds or dominant frequency in single-twitch sounds.

Most fishes that use sonic swimbladder muscles for sound production vocalize at relatively low frequencies that fit the forced-twitch model. For example, sonic muscles in the oyster toadfish can

*Correspondence to: Michael L. Fine, Department of Biology, Virginia Commonwealth University, Richmond, VA 23284-2012.

E-mail: mfine@vcu.edu

Published online 00 Month 2007 in

Wiley InterScience (www. interscience.wiley.com)

DOI: $10.1002 /$ jmor. 10551 

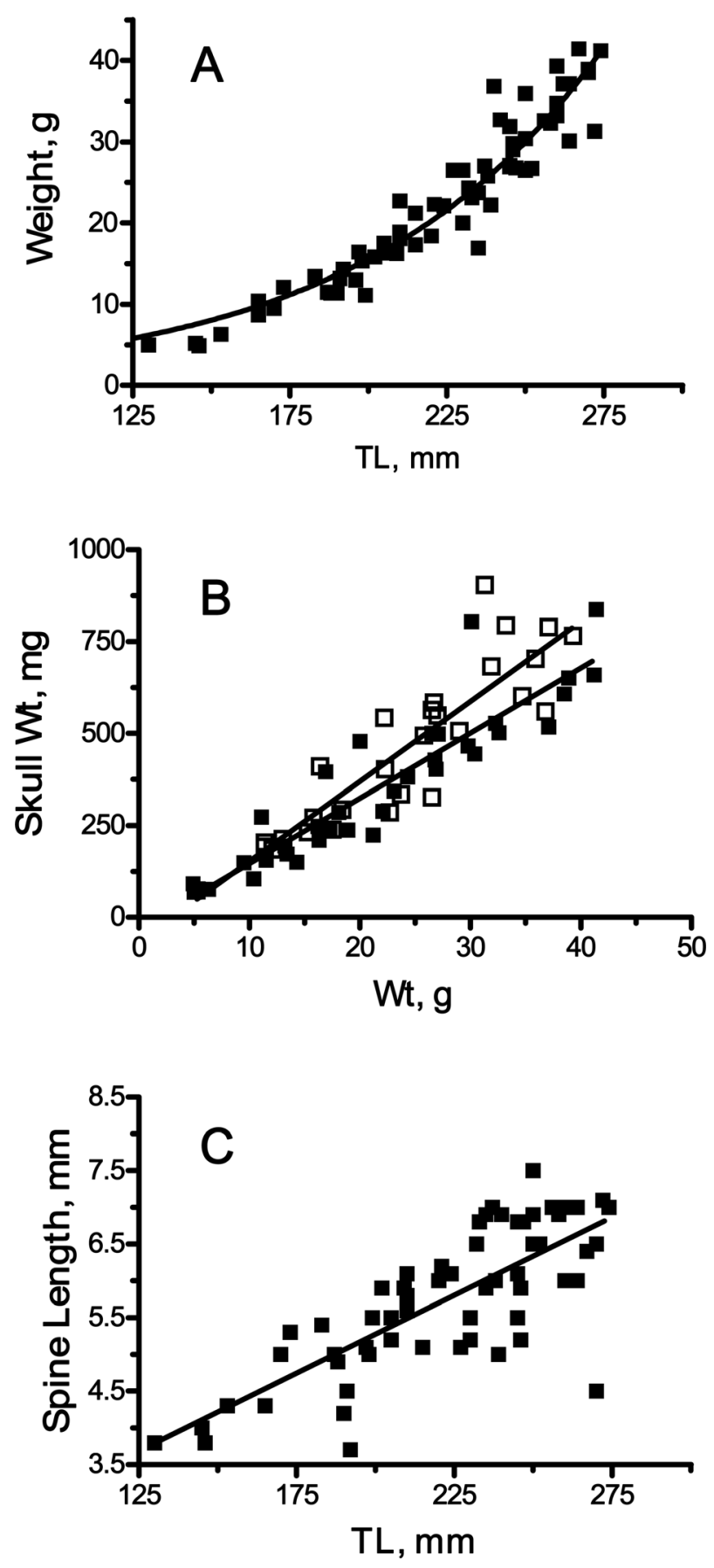

Fig. 1. A: Relationship of weight to length for combined males and females in Lepophidium profundorum: $Y=$ $1.116 e^{0.01316 X}, r^{2}=0.90$. B: Relationship of skull weight to fish weight: Males: $Y=-64.91+21.72 X, r^{2}=0.80$, Females: $-31.51+17.74 X, r^{2}=0.84$. C: Relationship of spine length to total length for combined males and females: $Y=1.041+$ $0.02118 X, r^{2}=0.60$.

follow an electrical stimulus at $400 \mathrm{~Hz}$ without tetany (Fine et al., 2001) although the highest fundamental frequencies of toadfish recorded in nature approach $300 \mathrm{~Hz}$ (Fine, 1978; Thorson and Fine, 2002; Remage-Healey and Bass, 2005). Single- twitch sounds can have higher dominant frequencies, and the maximum for the weakfish Cynoscion regalis is above $500 \mathrm{~Hz}$ (Connaughton et al., 2002). Note that high frequency components in fish sounds (e.g., those above the peak frequency) represent higher order vibrations of the swimbladder and not the driving frequency. In many cases, these high frequency components may be above the fish's auditory range and therefore irrelevant to communication (Ladich and Fine, 2006).

Ophidiids, the dominant group of benthic deepsea fishes in both numbers and species in tropical and subtropical areas (Howes, 1992; Nielsen et al., 1999; Music personal communication), have swimbladder muscles, implicating them in sound production (Marshall, 1967). Recent descriptions of the sounds produced by a shallow-water ophidiid, Ophidion marginatum, indicate a dominant frequency above $1 \mathrm{kHz}$ (Mann et al., 1997; Perkins, 2001; Sprague and Luczkovich, 2001; Rountree and Bowers-Altman, 2002). This frequency is too high to be explained by the twitch model because no vertebrate muscle is known to complete a twitch in less than $1 \mathrm{~ms}$. We examined the sonic anatomy underlying potentially high frequency sound production in the fawn cusk-eel Lepophidium profundorum, a species that lives on the outer continental shelf in the Northwest Atlantic Ocean (Collette and Klein-MacPhee, 2002) and whose sounds have not been recorded. Although direct evidence is lacking, we are proceeding under the hypothesis that other ophidiids, but not related carapids (Parmentier et al., 2006b), likewise produce high frequency sounds. Several previous studies in ophidiids have clarified parts of the mechanism and indicate considerable variability within the sonic anatomy of the family (Rose, 1961; Courtenay, 1971; Carter and Musick, 1985; Howes, 1992; Casadevall et al., 1996; Parmentier et al., 2006a). These studies have noted sexual dimorphism in sonic structures, and the present study quantifies sexual differences for the first time.

\section{MATERIALS AND METHODS}

Fawn cusk-eels Lepophidium profundorum (Gill, 1863) were captured by otter trawl and frozen aboard Albatross IV cruises. Fish were collected from Cape Hatteras to the Gulf of Maine at depths of about $50 \mathrm{fm}$ from spring (March and April) and fall (September and October) bottom trawl surveys in 2001, 2002, and 2004.

Specimens were weighed to $0.1 \mathrm{~g}$ and measured for total length (TL) to the nearest millimeter, and gonads were exposed to determine fish sex. Fish were dissected to expose muscles attached to the swimbladder or to processes that connect to the bladder, and the origin and insertion of these muscles were described. We measured muscle length between the origin and insertion and length of the tendons protruding from the ventral muscle. Muscles (the right muscle of each pair) were weighed in milligrams after soaking in $0.9 \% \mathrm{NaCl}$ for $5 \mathrm{~min}$ and blotting to ensure uniform hydration. Swimbladder length and weight 

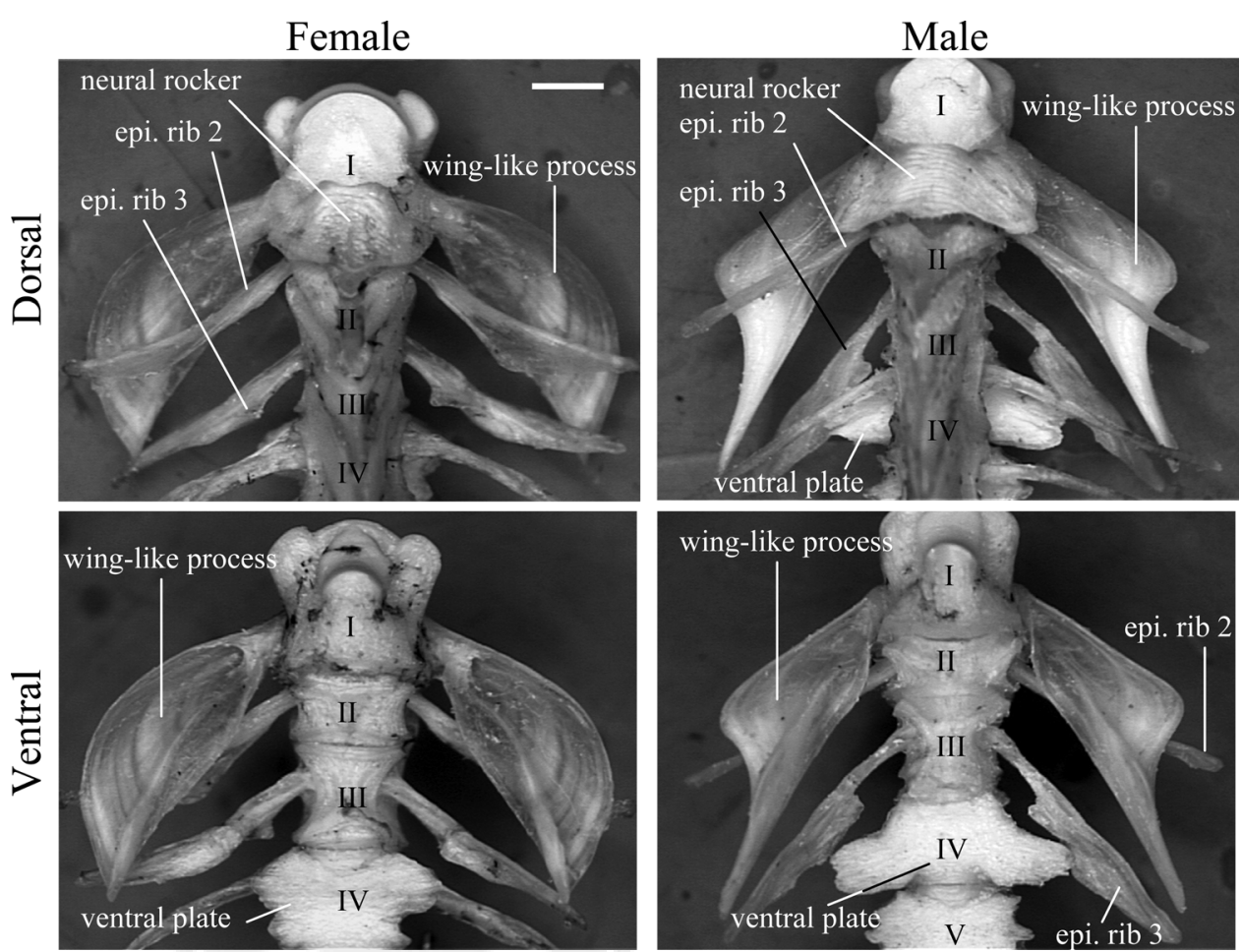

Fig. 2. Dorsal and ventral view of vertebrae I-V and epineural ribs in male and female Lepophidium profundorum.

\begin{abstract}
were also measured. Dissected specimens were placed in hot water with soap to facilitate tissue removal to expose the skeleton. We measured the length of the rostral spine, the dry weight of the neurocranium (hereafter referred to as the skull) and the length, height, and weight of the winglike process and weight of the "neural rocker." The neural rocker and winglike process were broken at a suture allowing us to weigh the two components individually.

Quantitative data from the skeleton, swimbladder, and sonic muscles were regressed against fish size (weight and total length), and sexual differences were determined by analysis of covariance. We used regressions to calculate adjusted means to compare male and female characters for a medium-sized individual (225 mm TL and $25 \mathrm{~g}$ ).
\end{abstract}

\section{RESULTS}

Fish ranged from 130 to $274 \mathrm{~mm}$ TL and included 36 females and 29 males. Size distributions were similar for both sexes, and males and females were not distinguishable externally. They had equivalent length-weight regressions, which were therefore combined into a single regression $\left(Y=1.116 e^{0.01316 \mathrm{TL}}, r^{2}=0.90\right)$ (Fig. 1A, Table 2$)$.

Skull weight increased linearly with fish weight (male $r^{2}=0.84$, female $r^{2}=0.80$ ) (Fig. 1B, Table 2). Although there was considerable overlap between males and females, skulls were heavier in males than in females $\left(F_{1,60}=6.1988, P=\right.$ 0.0156). Notably, a keel on the midline of the caudal part of the parasphenoid, which separates the right and left ventral sonic muscles (see below), was sufficiently deeper in males that this character can be used to determine fish sex. The spine on the snout, which is not visible externally, increased linearly with fish size with no sexual difference (Fig. 1C). The combined $r^{2}$ value $(0.60)$ was fairly low because some spines were broken despite being housed within tissue. Although likely defensive, spine function is unknown, and these observations appear to rule out a courtship function or a contribution to sexual dimorphism in head weight.

\section{Sonic Mechanism}

Skeleton. The first five vertebrae bear epineural ribs of different sizes (Figs. 2, 6, and 7). The first vertebra bears a large complex process consisting of an expanded rib, the winglike process, and a neural arch with two small median articulation heads that fit within depressions on the side of the first vertebra (Figs. 2 and 3 ). These two attachments confine movement to a single plane: the neural arch and spine pivot (rock back and forth) in the anteroposterior direction. We refer to this structure as the neural rocker to distinguish it from the rocker bone found in the anterior swimbladder wall in other ophidiids (Rose, 1961; Casadevall et al., 1996). The neural rocker is larger in males (Tables 1 and 2, Fig. 8) and has expanded lateral shoulders compared to a more rounded contour in females (Figs. 2 and 3). The winglike process is fused to the anterolateral base of the neural rocker at a suture, and the two can be removed as a single structure. The medial half
301 

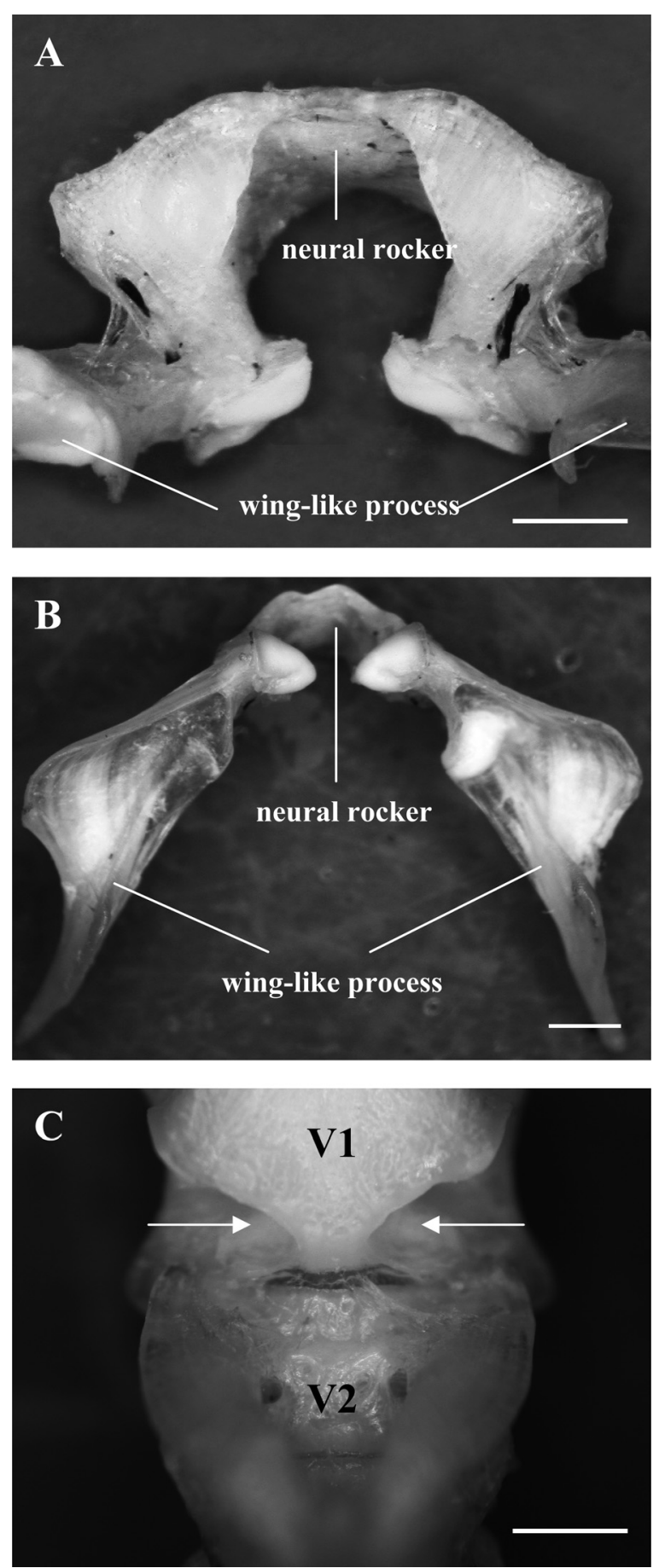

Fig. 3. Neural rocker (first neural arch), winglike process (WLP) and pivot joint in Lepophidium profundorum. Note the broad shoulders on the neural rocker in $\mathbf{A}$, the expanded tip of the WLP and the projections of the pivot joint in $\mathbf{B}$, which fit into the recesses in the vertebra in $\mathbf{C}$. Scale bar $=1 \mathrm{~mm}$.

of the winglike process is concave and narrows laterally to a ridge with a crest on the lateral margin. The crest is deeper in males than in females, and the expanded tip of the winglike process is narrower and more pointed in males than in females
(Fig. 2). The width of the winglike process is slightly wider in males than in females and considerably longer in males because of the distal tip (Figs. 2 and 8). A ligament on the ventrolateral surface of the winglike process (SWB ligament 1a) connects to the anterior face of the swimbladder (SWB) (Figs. 2, 5, and 7).

The remaining epineural ribs (EP2-5) have a single slender articulation head that would allow them to move in different directions except that movement is restricted by their attachments, which forms a scaffold over the anterior bladder (Figs. 2 and 7). The winglike process connects to EP2 by a ligament (SWB ligament 1b), and the tip of EP2 bears a ligament (SWB ligament 2) that connects to the swimbladder (Fig. 7). EP3 is thin proximally and becomes broader laterally binding to the bladder with connective tissue. The proximal part of EP3 connects to the osseous plate on vertebra 4 , which should restrict forward movement of the rib and stabilize the bladder. The osseous plate is larger with a greater lateral extension in males than females (Table 2). A smaller but similar structure is present on vertebra 5 .

Swimbladder morphology. The swimbladder is a slender sac consisting of a single chamber, which increases in girth from the anterior end for a short distance before gradually tapering. The bladder ends in a tail that is longer in females than in males (Figs. 4 and 5C). The bladder lies under the first through twelfth vertebrae and is tightly coupled to the vertebral column through the ninth vertebra. Again note particularly the broad attachment site on the osseous plate on the fourth and to a lesser extent on the fifth vertebra (Figs. 2 and 7). Interestingly, the posterior portion of the bladder is less closely attached but held to the 10th through 12th vertebrae by three strong string-like bands of connective tissue (Fig. 4C). The bladder has a similar length in males and females but is considerably heavier in males (Tables 1 and 2, Fig. 9).

The bladder may be divided into three regions. The anterior region is notably thickened and is the attachment site for sonic muscle ligaments (described above) and tendons (described under muscles). The second region, termed the swimbladder fenestra in ophidiiform fishes (Howes, 1992), is thin and transparent without an outer collagenous covering (Fig. 5A,B). The final region, the remainder of the bladder, is tightly coupled to the vertebral column, and begins at epineural rib 3 (EP3). The fenestra in males covers three-fourths of the swimbladder circumference and is larger dorsally tapering around the bladder sides (Fig. 5A). In females, the smaller fenestra is restricted to the dorsal surface. The anterior lip of the fenestra (ALF) is notably thickened and is the insertion site of SWB ligament 2 . The fenestra is more flexible than other bladder tissue and permits muscle 
TABLE 1. Summary of sexually dimorphic characters in the sonic system of Lepophidium profudorum

\begin{tabular}{lll}
\hline Character & \multicolumn{1}{c}{ Male } & \multicolumn{1}{c}{ Female } \\
\hline Ventral muscle & Heavier and thicker & Lighter and thinner \\
Intermediate muscle & Lighter and narrow & Heavier and wide \\
Dorsal muscle & Heavier and thicker & Lighter and thinner \\
Parasphenoid keel & Wide & Narrow \\
Posterior tip of the swim bladder & Short & Elongated \\
Swim bladder fenestra & Wide and long & Narrow and short \\
Ligament between EP1 and EP2 & Thin & Large, ligament runs to EP3 \\
Ventral plate on the 4th vertebra & Large & Small \\
Wing-like process & Elongated posterior tip & Shorter tip \\
Neural rocker & Larger with flattened dorsal & Thin and rounded \\
& aspect and lateral shoulder & \\
\hline
\end{tabular}

attachments to displace the anterior wall of the bladder (region 1). Dorsally, the region just caudal to the posterior edge of the fenestra attaches to EP3, and, as stated previously, the motion of this rib is severely restricted by ligament EP3-EP4, which connects the proximal end of EP3 to the osseous plate on vertebra 4 . This connection, as well as the tight coupling of the dorsal swimbladder wall to the vertebral column, will hold the posterior bladder relatively rigid during sonic muscle contraction.

Sonic muscles. The fawn cusk-eel has four pairs of sonic muscles (ventral, intermediate, dorsal and dorsomedial), all of which insert on the swimbladder or skeletal elements that move the swimbladder (Figs. 4, 5A, 6, and 7). These muscles have been given various names in other ophidiids; for instance, the ventral muscles have been referred to as M1 (Rose, 1961), primary sonic muscle (Courtenay and McKittrick, 1970), ventrolateral and ventromedial sonic muscles (Carter and Musick, 1985), and anterolateral segment of the epaxial muscle (Howes, 1992). Hopefully the terminology used here and in Parmentier et al. (2006a) will become standard.
Ventral muscle. The ventral muscles originate broadly on the flattened parasphenoid and are separated by a vertical keel, which is more extensive in males than females (Figs. 6 and 7). These muscles end in a long tendon that bifurcates. The straight portion runs directly to its insertion on the midportion of the ridge crest on the ventral winglike process (Figs. 4, 6, and 7). The ventral muscle tendon branches at a right angle, forming an intermuscular tendon that connects to the opposite ventral muscle tendon after running through the thickened anterior wall of the swimbladder (Figs. 4B and 5A). Thus, the ventral muscle forms an indirect lateral and a direct medial attachment to the swimbladder.

Intermediate muscle. The intermediate muscle originates on a protrusion situated behind the foramen of the vagal nerve on the anterior part of the basioccipital (Fig. 6). The muscle is narrow and runs beneath Baudelot's ligament in males, whereas in females it is wider and surrounds the ligament. The insertion of the intermediate muscles, medial to the insertion of the ventral muscles, is on a curved ridge that travels down the ventral side of the winglike process. The ridge

TABLE 2. Sexual dimorphism of sonic structures in Lepophidium profundorum

\begin{tabular}{lccc}
\hline Structure & Male & Female & Probability \\
\hline Ventral muscle $L(\mathrm{~mm})$ & 13.6 & 11.8 & $<0.0001$ \\
Ventral muscle Wt $(\mathrm{mg})$ & 78 & 54 & $<0.0001$ \\
Intermediate muscle $L(\mathrm{~mm})$ & 7.8 & 7.6 & $\mathrm{NS}$ \\
Intermediate muscle Wt $(\mathrm{mg})$ & 6.7 & 13.5 & $<0.0001$ \\
Dorsal muscle $L(\mathrm{~mm})$ & 10.9 & 9.4 & $<0.0001$ \\
Dorsal muscle Wt $(\mathrm{mg})$ & 80 & 38 & $<0.0001$ \\
Ventral muscle tendon L, (mm) & 3.1 & 2.2 & 0.038 \\
Intermuscular tendon L (mm) & 2.8 & 3.1 & $\mathrm{NS}$ \\
WLP width $(\mathrm{mm})$ & 2.5 & 2.2 & 0.0028 \\
WLP length $(\mathrm{mm})$ & 7.4 & 5.9 & 0.0018 \\
WLP weight $(\mathrm{mg})$ & 14.9 & 7.4 & $<0.0001$ \\
Neural rocker Wt (mg) & 6.7 & 3.6 & 0.0003 \\
Swimbladder $L(\mathrm{~mm})$ & 31 & 31 & $\mathrm{NS}$ \\
Swimbladder Wt $(\mathrm{mg})$ & 511 & 363 & 0.0006 \\
\hline
\end{tabular}

Adjusted means were calculated for a $225 \mathrm{~mm}$ TL or $25 \mathrm{mg}$ fish using regressions for males and females; Probability values were taken from analysis of covariance; In many cases (see graphs), the slopes were equal in which case the $P$ value indicates significance of elevation. 

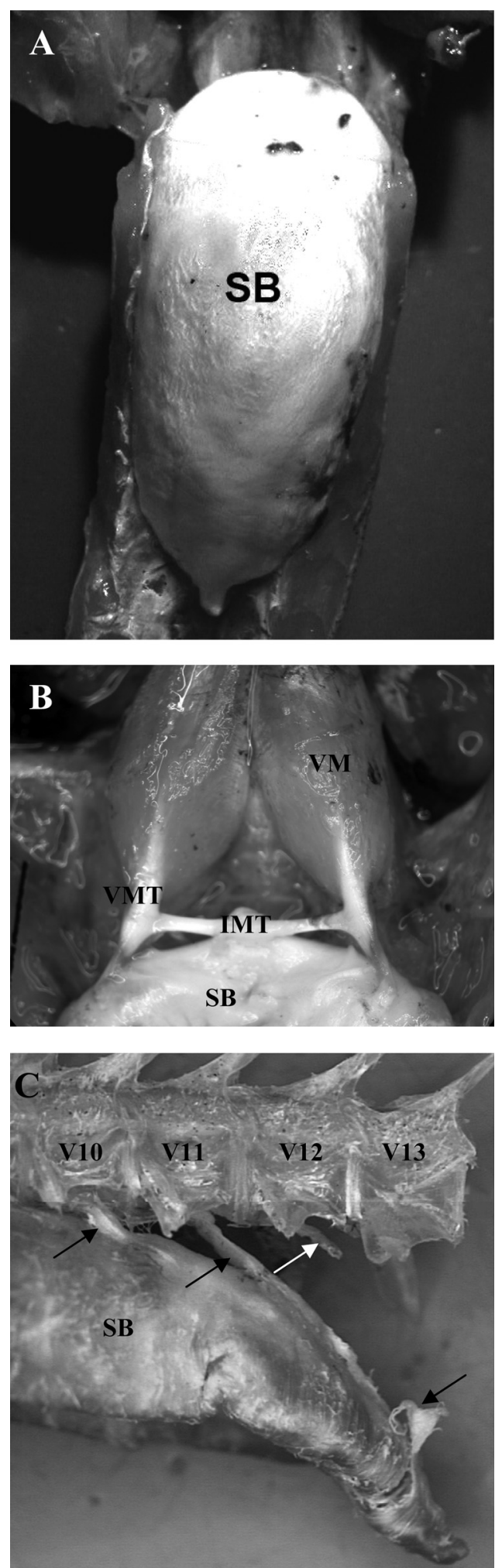

Fig. 4. A: The swimbladder of Lepophidium profundorum. B: The ventral muscles (VM) with the protruding ventral muscle tendon (VMT) that attaches to the WLP, and the intermuscular tendon (IMT) that enters the anterior wall of the bladder. The anterior wall has been cut away to reveal the tendon. C: Stringlike connective tissue attachments from vertebrae 10-12 to the posterior bladder. forms a posterior border of a concave surface on the process.

Dorsal muscle. The dorsal muscle originates on the epiotic, exoccipital, and the anterior portion of the supraoccipital crest (Fig. 6A,B) and extends to the lateral posterior portion of the dorsal surface of the neural rocker (Figs. 6 and 7). A medial dorsoventrally compressed dorsomedial muscle (DMm), described here for the first time, connects the posterior tip of the supraoccipital to the apex of the neural rocker.

\section{Relative Growth and Sexual Dimorphism}

The dorsal, intermediate, and ventral sonic muscles exhibited a linear increase in length and weight with fish size and were sexually dimorphic (Tables 1 and 2, Fig. 10). The dorsal and ventral 6 muscles were larger in males, but the intermediate muscle was larger in females. The dorsal muscle in males had an adjusted mean weight of $80 \mathrm{mg}$ (calculated for a midsized $25 \mathrm{~g}, 225 \mathrm{~mm}$ TL fish), the ventral muscle $78 \mathrm{mg}$, and the thin intermediate muscle was considerably lighter at $6.7 \mathrm{mg}$. Comparable values in females were 38,54 , and $13.5 \mathrm{mg}$, respectively. Comparisons of the muscles within each sex (Table 2) indicate that the ventral 6 muscle is longer than the dorsal muscle in both sexes and heavier than the dorsal muscle in females; in males the two muscles were comparable in weight $(P>0.05)$. The intermediate muscles were shorter and lighter than the other two in both sexes.

Swimbladder lengths were similar in both sexes, but bladders were heavier in males (Table 2, Fig. 9 ). The tendon of the ventral muscle was longer in males, but intermuscular tendon length was similar in both sexes (Table 2, Fig. 9). Finally, the neural rocker was heavier in males as reflected in its broader structure (Figs. 2 and 8), and the winglike process was slightly wider, longer and therefore considerably heavier in males than in females (Table 2, Fig. 8). The increased length of the winglike process accommodates the longer ventral muscle and ventral muscle tendon in males. Since the ventral tendon inserts laterally on the slender tip of the winglike process, the longer ventral muscle in males should impart a greater torque on the winglike process, thereby increasing the movement of the swimbladder during sound production.

The regression of dorsal muscle weight against fish weight had a greater slope in males than in females as did ventral muscle tendon length, neural rocker weight, winglike process weight, and swimbladder weight (Figs. 8-10). However, muscle length of all three sonic muscles and weights of the ventral and intermediate muscles grew at an equivalent rate in both sexes (slopes were not significantly different) although structures were
661 

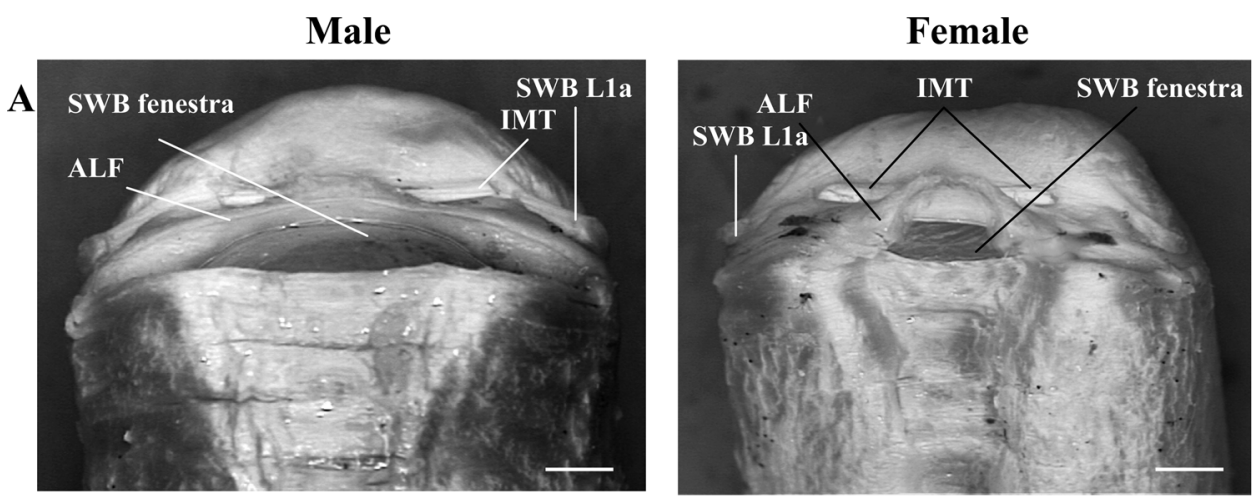

Fig. 5. Sonic specializations of the swimbladder in male and female Lepophidium profundorum. A: The intermuscular tendon (IMT), swimbladder fenestra, and anterior lip of the fenestra (ALF). B: The attachment of the ventral muscles (VM) to the WLP, WLP attachment to the bladder via tendon L1a, and the side view of the swimbladder fenestra in the male but not in the female. C: Swimbladder tail, which is longer in females than males.
B
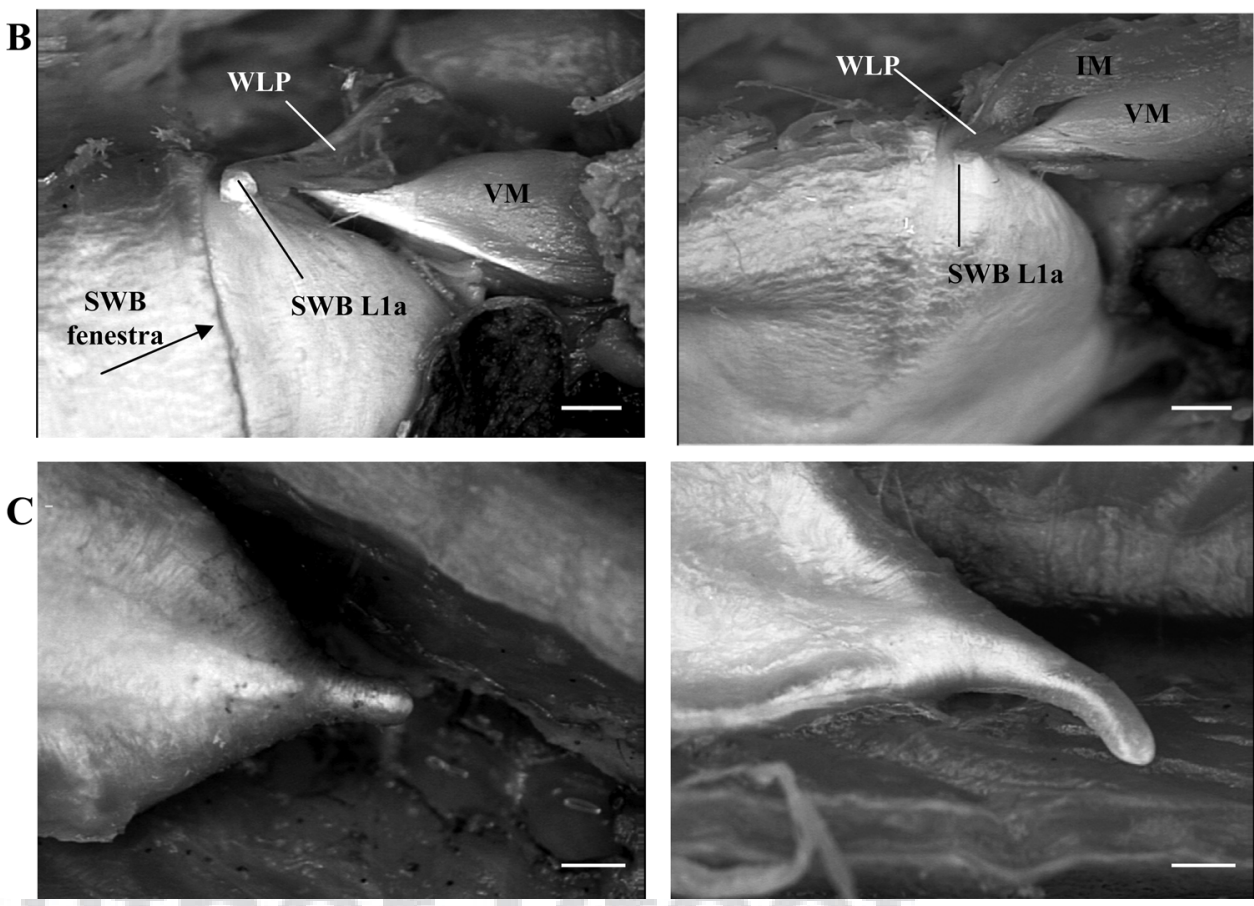

781

782

783

784

785

786

787

788

789

790

791

792

793

794

795

796

797

798

799

800

801

802

803

804

805

806

807

808

809

810

811

812

813

814

larger in one sex (e.g. males except for the intermediate muscles), indicative of significant differences in elevations of the regressions.

Function. Pulling on the ventral and intermediate muscles causes the winglike process to pivot forward thereby forcing the anterior surface of the swimbladder forward and downward, and thus stretching the swimbladder fenestra (Fig. 7). This process is aided by a series of connections (swimbladder ligaments $1 \mathrm{a}, 1 \mathrm{~b}, 2$, and the intermuscular tendon). Therefore, contraction of the ventral and intermediate muscles will place these elements under tension (Fig. 7). Motion of the winglike process causes the neural rocker to pivot backward until it is pinned against the dorsal spine of the second vertebra, which therefore functions as a stop to ventral muscle contraction. Contraction of the dorsal muscle antagonist pivots the neural rocker forward, restoring swimbladder position.

\section{DISCUSSION}

Knowledge of sound production in deep-sea fishes is circumstantial (Mann and Jarvis, 2004) and based mainly on anatomy, i.e., the presence of sonic swimbladder muscles (Marshall, 1967). To our knowledge, the striped cusk-eel Ophidion marginatum, which lives in shallow water, is the only identified ophidiid whose sounds have been recorded (Mann et al., 1997; Perkins, 2001; Sprague and Luczkovich, 2001; Rountree and Bowers-Altman, 2002), and its sound pulses have anomalously high peak frequencies exceeding $1 \mathrm{kHz}$. We started our investigation into the sonic anatomy of the fawn cusk-eel Lepophidium profundorum to uncover anatomical features that might lead to high frequency sound production. The discovery of antagonistic muscle pairs was disconcerting, since a muscle antagonist must slow down one action before starting another, thereby seemingly favor- 

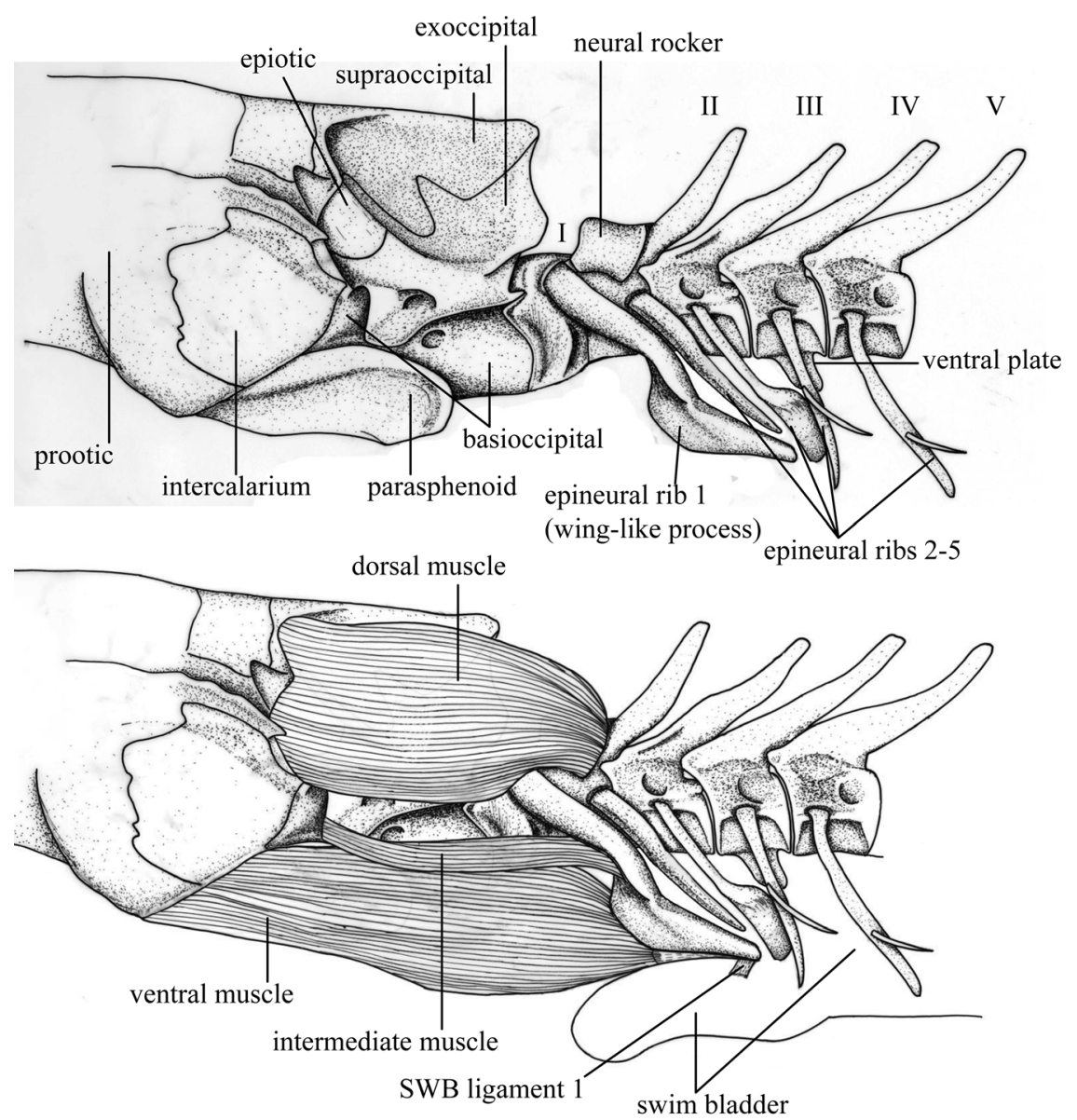

dorso-medial muscle



Fig. 6. Top: Drawing of the skull, first 5 vertebrae and epineural ribs in Lepophidium profundorum. Middle: Drawing of the ventral, intermediate, and dorsal muscles superimposed on the skeleton. Bottom: Micrograph of the sonic muscles.

ing lower rather than higher swimbladder vibration frequencies.

Swimbladder sounds typically result from forced responses to muscle contraction (Fine et al., 2001; Connaughton et al., 2002; Connaughton, 2004; Fine et al., 2004). However, a typical fish mecha-

nism of sound generation in cusk-eels would still require opposite movements of the muscle antagonists to occur in less than $1 \mathrm{~ms}$ to produce a sound with a dominant frequency above $1 \mathrm{kHz}$. Such speed is unlikely for muscle contraction or motor neuron control. Another avenue for generating 
Fig. 7. Top: Drawing of the skull and anterior vertebrae illustrating torque patterns of the ventral, intermediate, and dorsal muscles on the neural rocker and WLP. Bottom: Schematic diagram of the sonic apparatus including skeletal elements, tendons, and sonic muscles in male and female Lepophidium profundorum. Arrows in the right figure illustrate movements of ligaments, tendons, and the swimbladder fenestra during contraction of the ventral and intermediate muscles.
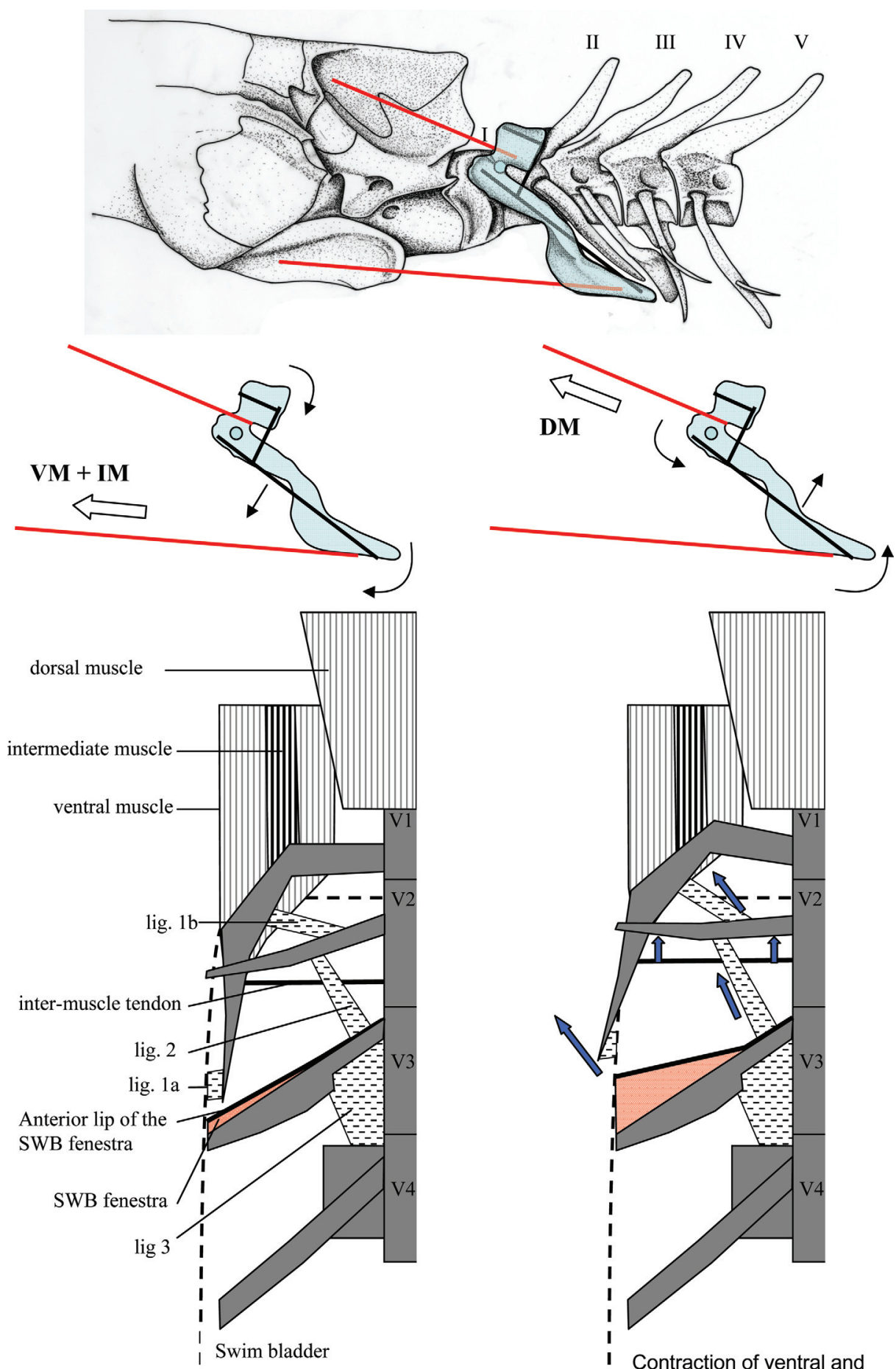

1021

I Contraction of ventral and intermediate muscles sounds has been demonstrated in carapid fishes, which are closely related to the ophidiids (Courtenay and McKittrick, 1970; Nielsen et al., 1999). Unlike all other sounds generated by fast sonic swimbladder muscles, sounds in Carapus acus are generated with slow muscles that require $490 \mathrm{~ms}$ for a twitch and that tetanize above $10 \mathrm{~Hz}$ (Par- mentier et al., 2006b). For comparison, toadfish sonic muscles require about $10 \mathrm{~ms}$ for a twitch and can follow an electrical stimulus at $400 \mathrm{~Hz}$ (Skoglund, 1961; Fine et al., 2001). Resonant frequency calculations (Weston, 1967) for an underwater bubble with an equivalent radius to the swimbladder in Carapus boraborensis predicted frequencies an 

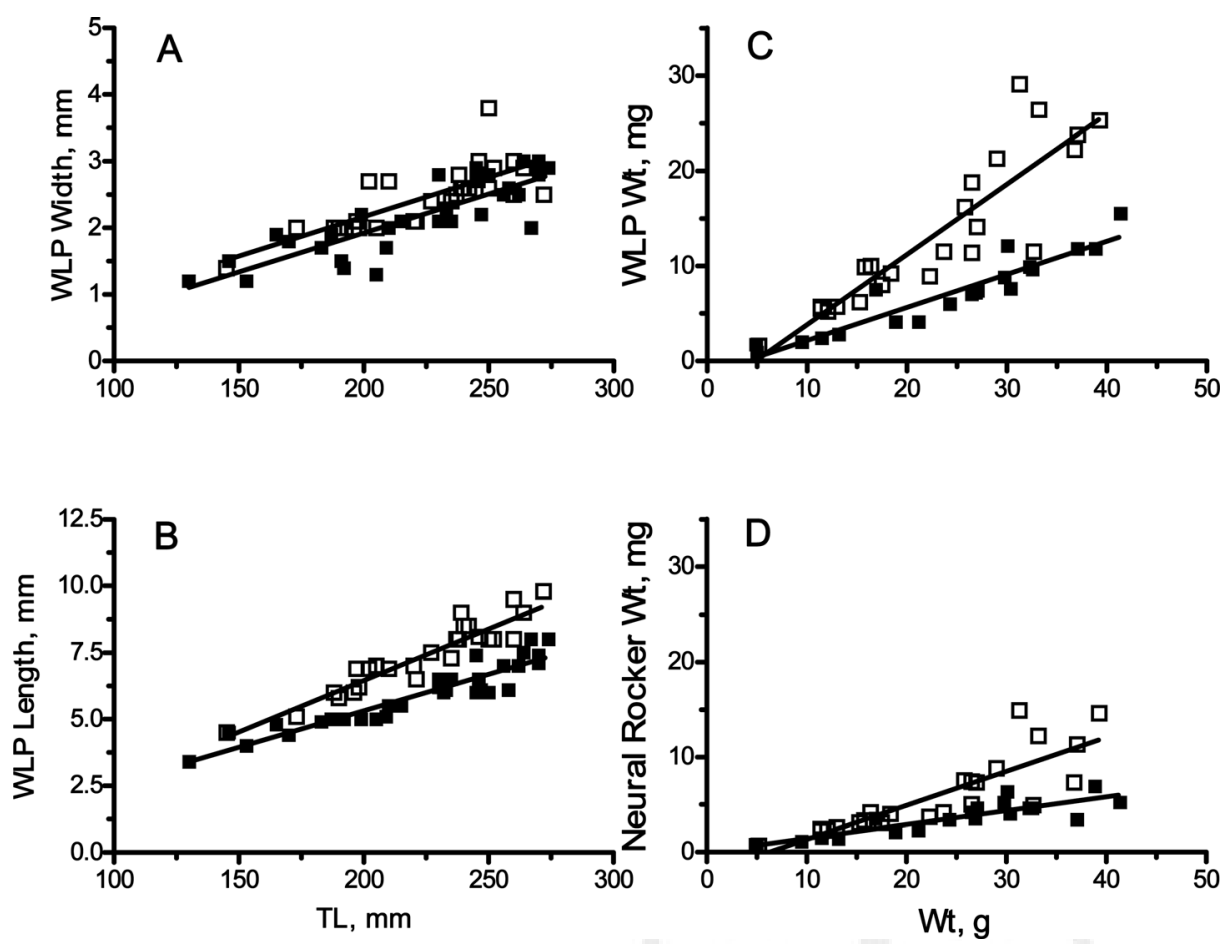

Fig. 8. Relationship of winglike process (WLP) and neural rocker to total length or weight in male and female Lepophidium profundorum. A: WLP width to TL. Males: $Y=-0.1981+0.01183 X, r^{2}=$ 0.60. Females: $Y=-0.4154+$ $0.01171 X, r^{2}=0.70$. B: WLP length to TL. Males: $Y=-1.27+$ 0.0386X, $r^{2}=0.87$. Females: $Y=$ $-0.1673+0.02741 X, r^{2}=0.88 . \mathbf{C}$ : WLP weight to fish weight. Males: 0.01183X, $r^{2}=0.60$. Females: $Y=$ $-0.4154+0.01171 X, r^{2}=0.70$ WLP length to TL. Males: $Y=$ $-1.27+0.0386 X, r^{2}=0.87$. Females: $Y=-1.296+0.3471 X$, $r^{2}=0.88$. D: Neural rocker weight to fish weight. Males $Y=-2.235$ $+0.3570 X, r^{2}=0.72$. Females: $Y$ $=-0.04565+0.1465 X, r^{2}=78$. octave higher than that produced by the fish (Parmentier et al., 2006b). Since the swimbladder of the fawn cusk-eel is larger than that of $C$. boraborensis, generation of high frequency sounds by bladder resonance is unlikely. A swimbladder fenestra (Howes, 1992), which decouples sonic muscleinduced movement of the anterior swimbladder from the rest of the structure, occurs in both carapids and ophidiids. Therefore, it is parsimonious to assume that fawn cusk-eel sounds are also induced by slow muscles. Another parallel between carapids and the fawn cusk-eel is the presence of modified ribs in close association with the swimbladder fenestra. In $C$. boraborensis, a broad modified rib, the swimbladder plate, is intimately connected to the fenestra, and Parmentier et al. (2006a) hypothesized that the plate is excited by the rapid return of the fenestra, which was stretched and then released by sonic muscle contraction; plate vibrations in turn were seen as driving the swimbladder and determining the sound frequency.

Although the carapid mechanism does not utilize antagonistic muscles, we see a number of parallels in the sonic mechanism in the fawn cusk-eel. The cusk-eel's ventral and intermediate muscles pull the swimbladder forward, pivoting the neural rocker backward until it hits the neural arch of the second vertebra, which should rapidly terminate motion. The ventral muscles will be more effective in deforming the swimbladder than the intermediate muscles because of their greater mass and length, greater tendon length, and more lateral insertion. It is conceivable that residual ventral and intermediate muscle contraction after the stop increases tension on the winglike process, tendons, and ligaments as if they were springloaded. The intermediate muscles have larger fibers than the ventral and dorsal muscles in Ophidion barbatum (Parmentier et al., 2006a), and it is therefore plausible that the intermediate muscles will be slower and maintain tension after the stop. Further, we hypothesize that the extended thin tips of the male winglike process are an adaptation to store strain energy (Alexander, 2002).

The ligament attaching the third epineural rib to the osseus plate on vertebra 4 plus the intimate attachments of the dorsal swimbladder to the vertebral column isolates the posterior bladder from muscle contractions. In fact, the system is designed to displace the anterior portion of the swimbladder forward primarily by stretching the fenestra. The complex bladder attachments of the ventral muscles (winglike process laterally and intermuscular tendon medially) act as a stay to keep the front of the bladder from buckling, thereby serving to transfer muscle work efficiently to bladder displacement. Swimbladder shape is restored by shorter antagonistic dorsal and dorsomedial muscles that work indirectly by pulling the neural rocker forward. Because of the pivot action and the longer winglike process, the dorsal muscles enjoy a mechanical lever advantage (for speed but not force) so that a short movement will be translated into a longer motion of the swim- 

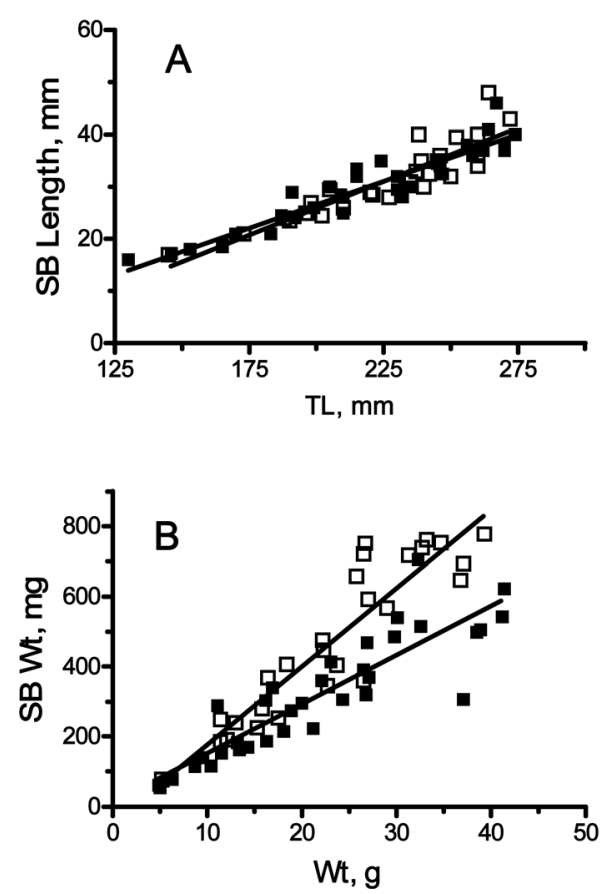
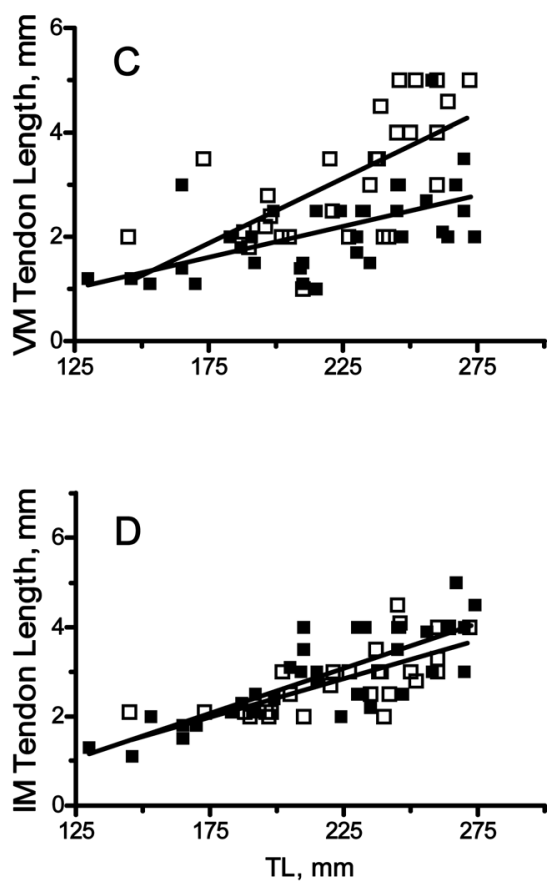

Fig. 9. Relationship of swimbladder length and weight to total length or weight and ventral muscle tendon and intermuscular tendon length to total length in male and female Lepophidium profundorum. A: Swimbladder length to TL. Males: $Y=-15.24+$ $0.2059 X, r^{2}=0.82$. Females: $-9.457+0.1803 X, r^{2}=0.89$. B: Swimbladder weight to fish weight. Males: $Y=-46.64+22.31 X, r^{2}$ $=0.84$. Females: $Y=10.96+14.06 X, r^{2}=0.79$. C: Ventral muscle tendon length to TL. Males: $Y=-2.477+0.02492 X, r^{2}=$ 0.43. Females: $Y=-0.4753+0.0119 X, r^{2}=0.31$. D: Intermuscular tendon length to TL. Males: $Y=-1.057+0.01735 X, r^{2}=$ 0.52. Females: $Y=-1.463+0.02017 X, r^{2}=0.63$

bladder. Measuring from the prongs that insert in the vertebra, the ratio of the height of the neural rocker to the length of the winglike process in a male is about 1:2.5. Therefore, a small forward movement of the rocker will exert a magnified displacement of the bladder approximating that ratio. However, the lever advantage of the dorsal muscles results in a force disadvantage. Since contraction of the dorsal muscles will release strain energy (Alexander, 2002) stored in the winglike process, tendons and epineural rib 2 (Fig. 7), dorsal muscle action should not require a great deal of force. The bladder should pop back rapidly, generating a rapid increase in pressure within the bladder. Note that the dorsal muscle in the striped cusk-eel undergoes a seasonal hypertrophy that should facilitate bladder return (Courtenay, 1971).

The bladder ends in a little tail, and similar tails are present in unrelated sciaenid fishes (Chao, 1978), suggesting convergent evolution. The wide anterior end of the bladder will admit high velocities courtesy of the fenestra, and the taper down to the more rigid posterior tail will concentrate the pressure of an acoustic wave and reflect it back to the anterior end where it could potentially reexcite tendons and ligaments, evoking a multicycle pulse. The swimbladder tail will not be an effective sound radiator because of its small surface area and resistance to movement, i.e., low volume veloc- ity (Bradbury and Vehrencamp, 1998), suggesting the flat surface of the bladder between the fenestra and the tail is primarily responsible for radiating sound.

Pivot joints in mammals permit a circular rotation (Marieb and Mallatt, 2001), e.g., the proximal radioulnar and alantoaxial joints in humans, which allow us respectively to rotate our forearm and our head from side to side. The attachment of the neural rocker to the first vertebra, a longitudinal pivot joint whose motion is restricted to the anterior-posterior plane, appears to be a new type of joint with low inertia and a stop that would favor high speed cycling.

Preliminary audiograms for the striped cusk-eel Ophidion marginatum indicate it is an auditory generalist with low frequency hearing (B. Casper and D. Mann, personal communication). They found an upper auditory limit of $800 \mathrm{~Hz}$ using the auditory brainstem response. We therefore suggest that the cusk-eel sonic mechanism evolved to produce high sound pressure levels with slow muscles and that high frequency sound production was generated incidentally, basically an epiphenomenon. Therefore, only low frequency components of the sound spectrum, those below the peak frequency, are likely to play a role in acoustic communication.

The phylogeny of ophidiiform fishes is poorly understood (Nielsen et al., 1999) and does not 

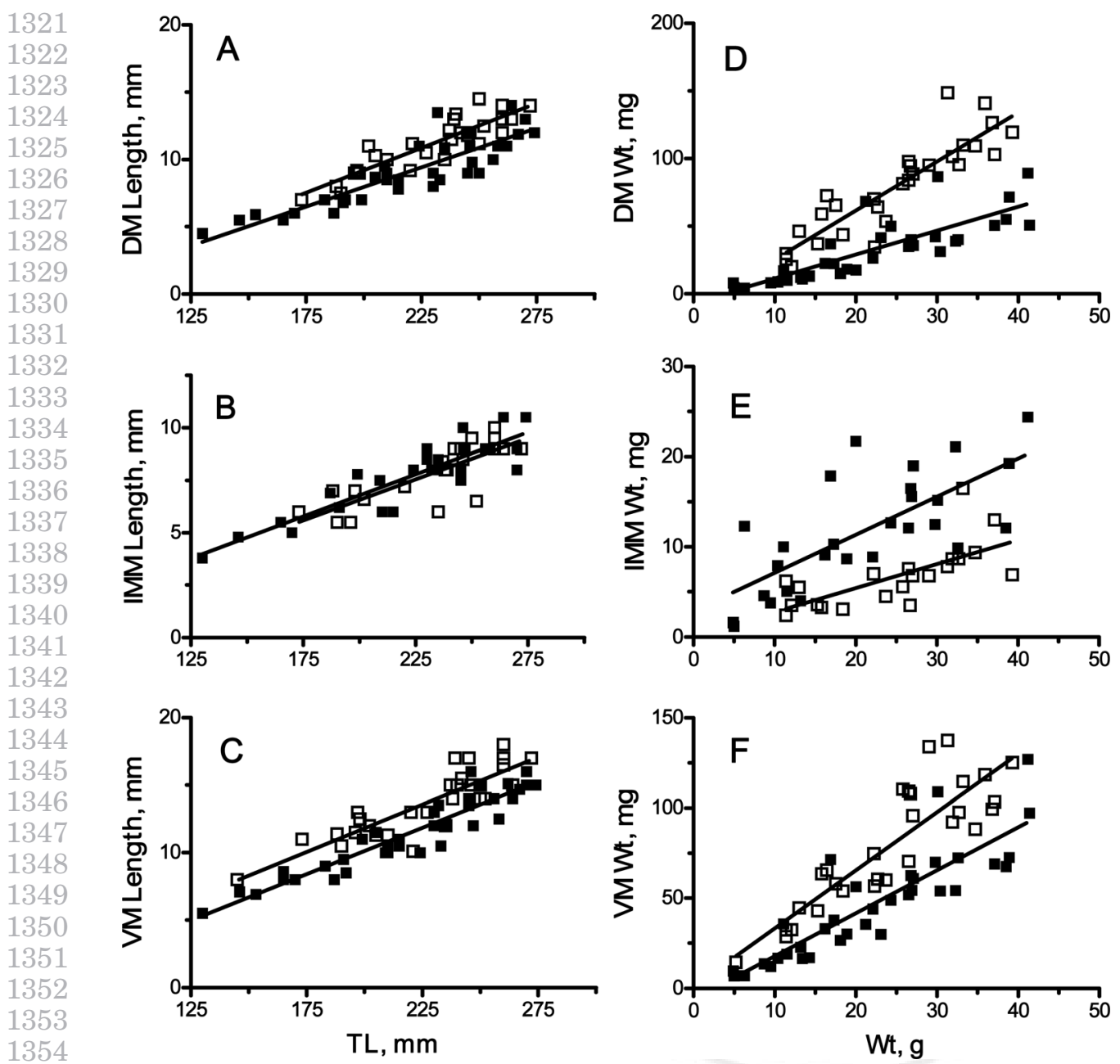

Fig. 10. Relationship of dorsal, intermediate, and ventral muscle length and weight to fish total length and weight in male and female Lepophidium profundorum. A: Dorsal muscle length to TL. Males: $Y=-4.139+0.06668 X, r^{2}$ $=0.80$. Females: $Y=-3.713+$ $0.05841 X, r^{2}=0.78$. B: Intermediate muscle length to TL. Males: $Y$ $=-1.237+0.03907 X, r^{2}=0.64$. Females: $Y=-1.227+0.4011 X$ $r^{2}$. C: Ventral muscle length to TL Males: $Y=-2.219+0.07009 X, r^{2}$ $=0.75$. Females: $Y=-3.641+$ $0.06883 X, r^{2}=0.88$. D: Dorsal muscle weight to fish weight. Males: $-11.22+3.638 X, r^{2}=$ 0.80. Females: $Y=-6.373+$ $1.769 X, r^{2}=0.68$. E: Intermediate muscle weight to fish weight. Males: $Y=0.00995+0.2668 X, r^{2}$ $=0.49$. Females: $Y=2.849+$ $0.4243 X, r^{2}=0.53$. F: Ventral muscle weight to fish weight. Males: $Y=6.986+2.836 X, r^{2}$ 0.54. Females: $Y=-6.197+$ $2.392 X, r^{2}=0.76$.

provide a clear platform for interpreting evolutionary changes in sonic morphology. Howes (1992) examined the morphology of a large number of ophidiids, including several aspects of the sonic system without considering function. He separated the ophidiids into two major patterns: (1) those with direct contacts between the swimbladder and expanded ribs, and (2) those in which the swimbladder is isolated from nonexpanded ribs. Our discussion here will concentrate on studies focused primarily on the sonic mechanism, which all appear to come from Howe's first group. These studies indicate extreme variability, and sonic mechanisms examined fall into three patterns. The simplest system is present in the deep-water Barathrodemus manatinus, collected from 1,8002,600 m (Carter and Musick, 1985). Males possess two ventral muscles (a lateral and a medial) that both originate on the prootic. The lateral muscle, present only in males, inserts on the swimbladder wall, and the medial muscle inserts broadly on ribs attached to vertebra 4 in males and females. Compared to development in more shallow forms, the muscles appear quite slender, and there is no neural rocker, rocker bone or winglike process. It is not currently possible to interpret this system as primitive or, rather, a degenerate adaptation to the deep sea. Splitting of the ventral muscles into lateral and medial components would argue that this adaptation is not basal.

The second basic pattern is found in the fawn cusk-eel (this study) and the striped cusk-eel Ophidion marginatum (Courtenay, 1971). Although there are major differences in swimbladder morphology, both species have ventral, intermediate, and dorsal muscles. Courtenay's ventral muscles (his primary sonic muscles) connect to the winglike process (his bladelike first ribs) in males but to thickened outpocketings of the anterior bladder in females. In the fawn cusk-eel, ventral muscles connect to the winglike process and swimbladder in both sexes. Courtenay finds a medial sound-producing muscle (= our intermediate muscle) only in females, whereas it is present in both sexes in the fawn cusk-eel and enlarged in females. Courtenay mentions that the dorsal muscles insert broadly on 
the distal anterior surfaces of the first neural spine (our neural rocker). Our thin dorsomedial muscle that inserts medially on the apex of the neural rocker has not been previously described. However, Courtenay states that the dorsal muscle is weakly attached to the medial surface of the spine with connective tissue that is easily torn. His observation could reflect the incipient formation or loss of this muscle. Notably, the dorsal muscle in the striped cusk-eel is so much larger than the ventral muscle in males that the structure can be recognized externally as a hump on the head. The fawn cusk-eel is sexually monomorphic, and the vental and dorsal muscles are similar in size in males in our spring and fall samples, both of which appear to be outside of the mating season.

The third pattern is present in some Ophidion (Ophidiidae) and Onuxodon (Carapidae), which have a rocker bone protruding from the front wall of the swimbladder (Rose, 1961; Tyler, 1970; Parmentier et al., 2006a). In Ophidion barbatum, successive contractions of the ventral and dorsal muscles cause counter clockwise and then clockwise rotation of the rocker bone, resulting in the inward and outward deformation of the swimbladder (Parmentier et al., 2006a). We suggest that the intermuscular tendon and the anterior wall of the swimbladder in the fawn-cusk-eel may be a precursor to the rocker bone (see also Parmentier et al., 2002; Parmentier and Diogo, 2006).

Measurements of sonic structures in this study provide the first quantitative treatment of sexual dimorphism in this family. Larger intermediate muscles in female fawn cusk-eels and their presence in females but not males in striped cusk-eels (Courtenay, 1971) clearly reverses the normal trend in sound production in which a sonic mechanism is either larger or present only in males of many fish species (Ladich and Fine, 2006). Several structures in the male (notably dorsal muscle weight, ventral muscle tendon length, neural rocker weight, winglike process weight, and swimbladder weight) grow at a greater rate in males suggesting androgenic control (Fine and Pennypacker, 1986; Connaughton and Taylor, 1995; Fine, 1997). However, the occurrence of similar slopes yet significant differences in lengths for all sonic muscles in males and females is difficult to interpret. The same is true for equivalent regression slopes of the ventral and intermediate muscle weights between males and females. One possible cause would be a hormonal effect during a critical period coinciding with initial gonad maturation. The greater muscle lengths and weights, extended tips on the winglike process, and a more massive swimbladder with a more developed fenestra suggest that males are capable of producing more intense sounds than females, presuming that females can call at all.

\section{ACKNOWLEDGMENTS}

Samples were collected during fishery independent bottom trawl surveys and were provided by the Ecosystem Surveys Branch of the Northeast Fisheries Science Center, NOAA Fisheries. Our thanks to Peter Chase for helping us procure the fish and to Michael Fahay for providing some fixed specimens.

\section{LITERATURE CITED}

Alexander RM. 2002. Tendon elasticity and muscle function. Comp Biochem Physiol A 133:1001-1011.

Amorim MCP, Hawkins AD. 2005. Ontogeny of acoustic and feeding behaviour in the Grey Gurnard Eutrigla gurnardus. Ethology 111:255-269.

Bass AH, Baker R. 1991. Evolution of homologous vocal control traits. Brain Behav Evol 38:240-254.

Bass AH, McKibben JR. 2003. Neural mechanisms and behaviors for acoustic communication in teleost fish. Prog Neurobiol 69:1-26.

Bradbury JW, Vehrencamp SL. 1998. Principles of Animal Communication. Massachusetts: Sinauer.

Carter HJ, Musick JA. 1985. Sexual dimorphism in the deepsea fish Barathrodemus manatinus (Ophidiidae). Copeia 1985:69-73.

Casadevall M, Matallanas J, Carrasson M, Muñoz M. 1996 Morphometric, meristic and anatomical differences between Ophidion barbatum L., 1758 and O. rochei Müller, 1845 (Pisces, Ophidiidae). Publ Esp Inst Esp Oceanogr 21:45-61.

Chao LN. 1978. A basis for classifying Western Atlantic Sciaenidae (Teleostei: Perciformes). Washington DC: National Oceanic and Atmospheric Administration.

Collette BB, Klein-MacPhee G. 2002. Bigelow and Schroeder's Fishes of the Gulf of Maine, 3rd ed. Washington: Smithsonian Institution.748 p.

Connaughton MA. 2004. Sound generation in the searobin (Prionotus carolinus), a fish with alternate sonic muscle contraction. J Exp Biol 207:1643-1654.

Connaughton MA, Taylor MH. 1995. Effects of exogenous testosterone on sonic muscle mass in the weakfish, Cynoscion regalis. Gen Comp Endocrinol 100:238-245.

Connaughton MA, Fine ML, Taylor MH. 2002. Weakfish sonic muscle: Influence of size, temperature and season. J Exp Biol 205:2183-2188.

Courtenay WR. 1971. Sexual dimorphism of the sound producing mechanism of the striped cusk-eel, Rissola marginata (Pisces: Ophidiidae). Copeia 1971:259-268.

Courtenay WR, McKittrick FA. 1970. Sound-producing mechanisms in carapid fishes, with notes on phylogenetic implications. Mar Biol 7:131-137.

Crawford JD, Huang X. 1999. Communication signals and sound production mechanisms of mormyrid electric fish. J Exp Biol 202:1417-1426.

Fine ML. 1978. Seasonal and geographic variation of the mating call of the oyster toadfish Opsanus tau. Oecologia 36:4557.

Fine ML. 1997. Endocrinology of sound production in fishes. Mar Freshwater Behav Physiol 29:23-45.

Fine ML, Pennypacker KR. 1986. Hormonal basis for sexual dimorphism of the sound producing apparatus of the oyster toadfish. Exp Neurol 92:289-298.

Fine ML, Malloy KL, King CB, Mitchell SL, Cameron TM. 2001. Movement and sound generation by the toadfish swimbladder. J Comp Physiol A 187:371-379.

Fine ML, Schrinel J, Cameron TM. 2004. The effect of loading on disturbance sounds of the Atlantic croaker Micropogonius undulatus: Air vs. water. J Acoust Soc Am 116:1271-1275.

Howes GJ. 1992. Notes on the anatomy and classification of ophidiiform fishes with particular reference to the abyssal 


\section{M.L. FINE ET AL.}

genus Acanthonus Günther, 1878. Bull Br Mus Nat Hist (Zool) 58:95-131.

Ladich F, Fine ML. 2006. Sound-generating mechanisms in fishes: A unique diversity in vertebrates. In: Ladich F, Colin SP, Moller P, Kapoor BG, editors. Communication in Fishes. Enfield, New Hampshire: Science Publishers. pp 3-43.

Mann DA, Jarvis SM. 2004. Potential sound production by a deep-sea fish. J Acoust Soc Am 115:2331-2333.

Mann DA, Bowers-Altman J, Rountree RA. 1997. Sounds produced by the striped cusk-eel Ophidion marginatum (Ophidiidae) during courtship and spawning. Copeia 1997:610-612.

Marieb EN, Mallatt J. 2001. Human Anatomy, 3rd ed. New York: Benjamin Cummings.

Marshall NB. 1967. Sound-producing mechanisms and the biology of deep-sea fishes. In: Tavolga WN, editor. Marine BioAcoustics, Vol. 2. New York: Pergamon. pp 23-133.

Nielsen JG, Cohen DM, Markle DF, Robins CR. 1999. Ophidiiform Fishes of the World (order Ophidiiformes). Rome: FAO. FAO Species Catalog, Volume 18, 178 p.

Parmentier E, Diogo M. 2006. Evolutionary trends of swimbladder sound mechanisms in some teleost fishes. In: Ladich F, Collin SP, Moller P, Kapoor BG, editors. Communication in Fishes, Vol. 1. Enfield, New Hampshire: Science Publishers. pp 45-70.

Parmentier E, Chardon M, Vandewalle P. 2002. Preliminary study on the ecomorphological signification of the sound-producing complex in Carapidae. In: Aerts P, D'Août K, Herrel A, Van Damme R, editors. Topics in Functional and Ecological Vertebrate Morphology. Maastrich: Shaker Publishing. pp 139-151.

Parmentier E, Fontenelle N, Fine ML, Vanderwalle P, Henrist C. 2006a. Functional morphology of the sonic apparatus in Ophidion barbatum (Teleostei, Ophidiidae). J Morphol 267:1461-1468.

Parmentier E, Lagardère JP, Braquegnier JB, Vandewalle P, Fine ML. 2006b. Sound production mechanism in carapid fish: First example with a slow sonic muscle. J Exp Biol 209:2952-2960.
Perkins PJ. 2001. Drumming and chattering sounds recorded underwater in Rhode Island. Northeastern Nat 8:359-370.

Remage-Healey L, Bass AH. 2005. Rapid elevations in both steroid hormones and vocal signaling during playback challenge: A field experiment in Gulf toadfish. Horm Behav 47:297-305.

Rome LC, Linstedt SL. 1998. The quest for speed: Muscles built for high-frequency contractions. News Physiol Sci 13:261-268.

Rose JA. 1961. Anatomy and sexual dimorphism of the swim bladder and vertebral column in Ophidion holbrooki (Pisces: Ophidiidae). Bull Mar Sci 11:280-308.

Rountree RA, Bowers-Altman J. 2002. Soniferous behaviour of the striped cusk-eel Ophidon marginatum. Bioacoustics 12: 240-242.

Skoglund CR. 1961. Functional analysis of swimbladder muscles engaged in sound productivity of the toadfish. J Biophys Biochem Cytol 10:187-200.

Sprague MW. 2000. The single sonic muscle twitch model for the sound-production mechanism in the weakfish, Cynoscion regalis. J Acoust Soc Am 108:2430-2437.

Sprague MW, Luczkovich JJ. 2001. Do striped cusk-eels. Ophidium marginatum produce the 'chatter' sound attributed to weakfish, Cynoscion regalis (Sciaenidae)?. Copeia 2001:854859.

Tavolga WN. 1964. Sonic characteristics and mechanisms in marine fishes. In: Tavolga WN, editor. Marine Bio-Acoustics. New York: Pergamon. pp 195-211.

Thorson RF, Fine ML. 2002. Crepuscular changes in emission rate and parameters of the boatwhistle advertisement call of the gulf toadfish, Opsanus beta. Environ Biol Fish 63:321331.

Tyler JC. 1970. A redescription of the inquiline carapid fish Onuxodon parvibrachium, with a discussion of the skull structure and the host. Bull Mar Sci 29:148-164.

Weston DE. 1967. Sound propagation in the presence of bladder fish. In: Albers VM, ed. Underwater Acoustics, Vol 2. New York: Plenum. pp 55-88.

Winn HE. 1964. The biological significance of fish sounds. In: Tavolga WN, editor. Marine Bio-Acoustics. New York: Pergamon. pp 213-231.
1621 